\title{
Real wages and labor supply in a quasi life-cycle framework: a macro compression by Swedish National Transfer Accounts (1985-2003)
}

\section{Haodong Qi*}

\begin{abstract}
This paper examines the life-cycle dynamics of real wages and labor supply in Sweden. The descriptive results lend support to the inter-temporal substitution hypothesis (ISH), as the age patterns of real wages and the labor supply are both hump-shaped. However, the age-wage profiles increasingly shift toward older ages over time, whereas the age-employment profiles do not. This leads to an accentuated difference-in-differences of the two variables from prime working age through retirement, which casts doubt on the explanatory power of the ISH for the lifecycle labor supply. Econometric analysis shows that the intra-temporal elasticity outweighs the inter-temporal elasticity of substitution, and thus provides little support for the ISH. The estimated labor supply elasticity also varies considerably across age groups. This suggests that an array of age-specific parameters are needed in calibrating the overlapping generation model (OLG).
\end{abstract}

\section{Introduction}

In Sweden, a country at the forefront of best-practice life expectancy trends, life expectancy at birth is expected to reach 100 in about six decades (Oppen and Vaupel 2002). Coupled with the low fertility levels of recent decades, this trend is expected to result in growth in the share of the population who are aged 65+. Holding the mean age at retirement constant, this process implies that the per worker cost of providing a given age vector of per capita benefits will increase (Lee and Edwards 2001). These benefits include health care, elderly care, and other types of old-age social security programs. It might be argued that cutting benefits is one of the

\footnotetext{
${ }^{*}$ Haodong Qi, Centre for Economic Demography, Knut Wicksell Centre for Financial Studies, and Department of Economic History, Lund University, P.O. Box 7083, SE-220 07 Lund, Sweden.

Email: haodong.qi@ekh.lu.se.
} 
options for balancing the public budget; however, this simply shifts responsibility from the public to the private sector, and in no way addresses the consequences of population aging. In fact, it is possible that overall economic efficiency would deteriorate if some of the welfare services which are currently provided were shifted to the home, as family members might be forced to leave the labor market to provide care for the elderly.

Alternatively, if these expenditures are financed by national debt, intergenerational equity issues can arise, as future generations are expected to repay the debt. Unless the Ricardian equivalence proposition holds, ${ }_{1}^{1}$ public debt might crowd out private capital, erode productive investment, and depress economic output. In an open economy, the crowding-out effect may be attenuated by attracting foreign capital (Modigliani 1986), which could mitigate the loss of domestic capital and help to maintain the level of investment. However, as population aging is becoming a global phenomenon, it is unclear whether the inflow of foreign capital can sufficiently offset the crowding out of private capital. Moreover, while external debt can be issued, it still needs to be repaid by future generations; thus, the generational equity issue remains.

In Sweden, the cost of caring for the elderly is largely covered by tax revenues. Therefore, financing higher costs will involve either expanding the tax base or raising tax rates. Since the taxation levels in Sweden are already above the international average, broadening the tax base would appear to be a more reasonable solution. While demographic measures could help to enlarge the tax base, this strategy could create additional problems. For instance, if immigrant workers are poorly integrated into the Swedish labor market, increasing their numbers could place additional burdens on society. Initiatives to increase fertility, on the other hand, would not have positive effects on the size of the working population for at least 2530 years (Bengtsson and Scott 2011). Hence, a more realistic solution seems to be to increase the labor supply among the existing working-age population who are able to work.

Recent trends in Sweden toward better health among people in their sixties and seventies suggest that working life can be prolonged. However, during the first decade of this century, labor force participation in Sweden among people aged 65+ was low, at around 10 per cent. Meanwhile, youth labor force participation was declining, especially after the recession which began in $2008 .^{2}$ These patterns imply that policy measures which encourage early entry into and late exit from the labor market are needed to ensure the expansion of the tax base. This approach is likely to prove effective, because the young and the old together make up a large share of

\footnotetext{
1 Ricardian equivalence holds if bequests and gifts generate private flows which are large enough to offset changes in government deficit levels; thus, in this scenario there is no impact on short-run and long-run equilibrium (Barro 1974).

2 The data referred to in this discussion come from the Labor Force Statistics in OECD countries. Detailed information on how the statistics from different countries are compiled can be found at: www.oecd.org/els/employmentpoliciesanddata/LFSNOTES.
} 
Sweden's exploitable human resources. More importantly, if these groups remain outside of the workforce, they will place additional burdens on the welfare state.

To assess the long-term impact of population aging, we should consider various scenarios of labor supply. Gaining a thorough understanding of labor supply behavior is a sine qua non for formulating meaningful scenarios which would allow us to evaluate viable solutions to potential shortfalls. As the present study contributes to our understanding of the behavior of workers and trends in the labor supply, it has significant policy relevance.

Since the introduction of the inter-temporal substitution hypothesis (hereafter, ISH) by Lucas and Rapping (1969), the issue of labor supply has attracted enormous attention in macroeconomics. The ISH argues that the labor supply and wages should be positively correlated over the life-cycle. This is because the life-cycle wage profile is assumed to be foreseeable for individuals, a phenomenon known as 'evolutionary wage growth'. This wage pattern can generate substitution effects on the labor supply only if it is assumed that rational agents will concentrate their labor supply at ages at which their earning power is relatively high, and enjoy more leisure at ages at which their earning power is relatively low (Macurdy 1981).

So far, economists have been unable to agree upon the magnitude of this elasticity. Labor economists have typically obtained small estimates at the individual level, while macroeconomists have reported mixed evidence. Mankiw et al. (1985) found no statistical evidence supporting the ISH, while Alogoskoufis (1987) obtained higher estimates of intertemporal real wage elasticity than other economists. Lucas and Rapping (1969) have obtained the largest estimate of short-run labor supply elasticity with respect to wages, 1.4. They have claimed that this finding provides supporting evidence for the Keynesian-type assumption of a elastic short-run supply schedule. This paper contributes some new insights on this issue, as well as on some other unresolved questions.

There has been a long tradition of introducing age into macroeconomic models. The overlapping generational model with computable general equilibrium (OLGCGE) is one such framework. The model was pioneered by Samuelson (1958) and Diamond (1965), and was used by a number of followers in various applications (e.g. Auerbach and Kotlikoff (1987), Miles (1999), and Börsch-Supan (2003)).

All of these models assume that the elasticity of substitution does not vary over the life-cycle. The parameters for calibrating these models are mostly taken from aggregate time series analysis, without taking into account the age differentials. This leads to inconsistencies between the setting in which the empirical evidence is obtained and the setting in which estimated elasticities are applied.

In fact, aggregate estimates of time series data correspond to a model of a single representative agent who lives indefinitely. This differs from the overlapping generation (OLG) environment, where multiple agents have finite lives and coexist with different age groups at each point in time. Such estimated elasticity does not necessarily reflect the actual behavior of the agents at different stages of the life-cycle, which could eliminate the disproportional age-specific responses to macroeconomic change. 
For this reason, I use the National Transfer Accounts (NTA) for Sweden with time-varying age profiles of economic activity for the period 1985-2003 to estimate a life-cycle labor supply function. The estimation is theoretically consistent with the overlapping generation framework, and thus allows me to envisage a more realistic life-cycle model with age-separable elasticities of labor supply with respect to wages. This can serve as a new basis for future applications of OLG models.

The remainder of this paper is organized as following. First, I provide some theoretical considerations regarding the life-cycle real wage and labor supply. Next, I introduce various data sources and empirical models. In the following section, I report and discuss the results. Finally, I summarize some key findings in the conclusion.

\section{A general theory of real wage and labor supply - a lifecycle perspective}

\subsection{Age-wage differential}

Wage differentials between younger and older workers might be the result of a wage-productivity discrepancy, in which younger workers are underpaid and older workers are overpaid relative to their productivity (Skirbekk 2003). A few theories attempt to explain the existence of wage-productivity discrepancies and age-wage differentials.

The efficiency wage hypothesis argues that firms will be unconstrained by labor market conditions in pursuing their optimal recruitment policy, as long as the labor supply exceeds the demand, and the real wage offers are higher than the reservation wages (Yellen 1984). An extension of this hypothesis, the shirking model, seeks to explain why firms are willing to pay wages above the market rate. According to this model, the piece rate is an inaccurate measure of productivity, and overpaying workers relative to their productivity provides them with incentives not to shirk (Calvo 1979).

Additionally, economists have raised the question of why firms prefer to pay workers less when they are young and more when they are old with respect to their marginal product. This pattern is sometimes attributed to the nature of the optimal wage profile. A contracted pay schedule would lead to Pareto efficiency with mandatory retirement (Lazear 1981). Time spent in the labor market might also affect the wage distribution across age groups. Senior workers earn more on average, even if their perceived productivity is held constant. This is because they have had more time to bid up their wages, and their abilities can be more precisely assessed (Harris and Bengt 1982).

Finally, the age distribution of labor earnings might also be influenced by trade unions. If unions attach greater weight to the wishes of older workers than of younger workers, and if wages and employment are determined by efficient 
collective bargaining, the wages of older workers will always be higher than the wages of younger workers, regardless of productivity and labor supply (Pissarides 1989).

The time-varying age-wage patterns have rarely been examined in the current empirical literature, partly because yearly age profiles of wages are often unavailable. To the best of my knowledge, the only systematic investigation of the annual variation in the shape of the life-cycle earning profiles is a study for the U.S. which used the Current Population Survey 1962-2003. One of the major findings of that study is that there was a consistent upward trend in the earnings of older men relative to the earnings of younger men, which the authors attributed to the fact that younger workers no longer had an educational advantage over older workers (Lee et al. 2011).

In short, the theoretical literature generally predicts that younger workers tend to be underpaid relative to older workers. Hence, one of the purposes of the present study is to verify whether the age profile of labor income is in line with the theoretical predictions. I also attempt to determine whether in Sweden the earnings of older men have been rising relative to the earnings of younger men over time.

\subsection{The substitution and income effects on labor supply}

Based on the standard assumption that leisure is a normal good, an increase in real wages may be expected to have two potential effects on labor supply: i.e. substitution effects and income effects.

Based on these two opposite effects, micro-economists have predicted the possible shapes of the individual labor supply curve: i.e. a strictly positive supply curve and a backward-bending supply curve. The former curve suggests that the substitution effects consistently outweigh the income effects; while the latter curve implies that the substitution effects dominate only to a point at which both wages and working hours have reached a relatively high level, and that income effects then kick in and outweigh substitution effects. Accordingly, any further increase after a threshold of real wages and hours worked would induce individuals to reduce their labor to consume more leisure.

These two competing theoretical predictions lead us to ask an important question: Which curve better depicts the labor supply of individuals? So far, the empirical evidence indicates that a mixture of these two curves is needed to answer this question. Although the cross-sectional evidence on the short-run labor supply curve suggests that substitution effects dominate, at least for married women (Cain 1966; Mincer 1962), secular trends consistently provide support for the backward-bending supply curve, particularly in the long run. 


\subsection{The inter-temporal substitution hypothesis}

It is important to note that the preceding discussion on substitution and income effects has been restricted to the static analyses. For a comprehensive lifecycle analysis of labor supply, it is necessary to distinguish between the intratemporal effect and the inter-temporal effect; specifically, to disentangle the labor supply response to an unanticipated wage shift from the response to anticipated evolutionary wage growth. ${ }^{3}$

There are substantial differences between the two sorts of responses. The unanticipated wage shift can yield not only substitution effects, but also income effects, as was discussed above in the one-period analysis. The evolutionary wage growth, on the other hand, can generate only substitution effects. This is because when the life-cycle wage profile is foreseeable, rational agents will concentrate their labor supply over the ages at which their wages are high, and will demand more leisure over the ages at which their wages are low (Macurdy 1981). Such an assumption implies that the labor supply and the wage rate should be positively correlated over the life-cycle. This is called the inter-temporal substitution hypothesis (hereafter, ISH).

However, the empirical literature on this issue has so far provided inconsistent evidence. Mankiw et al. (1985) found no statistical evidence supporting the ISH using aggregate U.S. data. Alogoskoufis (1987), on the other hand, found substantially higher estimates of inter-temporal real wage and interest rate elasticities than others.

Such inconsistencies may be due to the measurement of the labor supply. Mankiw et al. (1985) used the aggregate man hours, which has been criticized as being the least important component by Heckman (1993). Alogoskoufis (1987) rather found strong inter-temporal elasticity when using numbers of employees and employment rates, but weak estimates when using total employee hours. This is not surprising, as in daily working life hours are not as flexible as is theoretically assumed. The pattern of hours worked over the life-cycle generally appears to be sticky, at least for male workers over the prime working ages. As a result, the responsiveness of the labor supply (measured by hours worked) to wage changes tends to be weak and insignificant. At an aggregate level, most of the variation in total man hours comes from variation in employment, not from hours worked per head (Coleman 1984). In addition, Heckman (1993) asserted that the strongest empirical effects of wages and non-labor income on labor supply are at the extensive margin, where the elasticity is unequivocally not zero.

3 A fuller discussion on this distinction is given in Macurdy (1981). 


\subsection{Labor supply elasticity in an overlapping generation setting}

Labor supply elasticities are important not only for understanding individual behavior, but also for addressing broader policy issues. For instance, in evaluating the financial stability of a pension system or experimenting with the welfare consequences of potential reforms, one common practice is to calibrate the estimated elasticities into an overlapping generation model with computable general equilibrium (OLG-CGE); e.g. Auerbach and Kotlikoff (1987); BörschSupan (2003); Miles (1999), etc. Two major issues arise when conducting this type of analysis.

The first issue is the decision about which parameter values to use, as estimated elasticities can vary depending on the source, and there is little consensus on their magnitude and representativeness. Prescott and Wallenius (2011) noted that aggregate elasticities are typically found to be larger than individual elasticities. This appears to support the argument that parameters should not be estimated in one setting and then applied to another. We can therefore assume that, OLG-CGE, as an abstracted macro model, should be calibrated by elasticities estimated at the aggregate level.

This leads us to the second issue: namely, that aggregate estimates of time series data may correspond to a single agent model with infinite life. This is not necessarily equivalent to the OLG setting, where multiple agents at different ages co-live at each point in time with a finite life span. Such estimated elasticities could eliminate the disproportionate impact of macroeconomic changes on various agents who are co-existing in the stylized environment at a given point in time. For example, the empirical evidence discussed earlier shows that young people were hit particularly hard during the recent recession (OECD 2011). Such unevenly distributed responses to business cycles cannot be reflected in OLG simulations if we assume that elasticities are constant over ages, and calibrate on the basis of estimates from aggregate data in the national accounts.

To the best of my knowledge, none of the existing OLG models have incorporated age-specific parameters governing inter- and intra-temporal decisions into the calibration. Furthermore, there have been very few macroeconomic studies which have empirically estimated age-specific elasticities.

Fair (1971) examined the relationship between wages, the money illusion, and labor force participation using quarterly data for the U.S. for the period 19561970. The variables used were age- and gender-specific. The study did not find any consistent labor supply responses to wages by different demographic groups, or any substantive differences between the wage and the money effects. One drawback of Fair's analysis is the lack of a theoretical foundation, both in terms of the variables chosen, the model specification, and the length of the distributed lags.

It is therefore necessary to estimate an empirical model which is consistent with the theory, and is applicable to the environment which the theoretical framework assumes. When seeking to estimate a labor supply function which is compatible with the OLG model, it is essential to emphasize the age differences in the estimated 
elasticities, and to specify the model in line with the theoretical framework. In other words, it is necessary to explicitly address the question of whether workers at different stages of the life-cycle could have had different inter-temporal and intratemporal responses to wage changes.

\section{A macro life-cycle model}

A new classical model of the dynamic household's labor supply and the firm's marginal productivity condition for labor was first introduced by Lucas and Rapping (hereafter, L-R model), and applied to the U.S. labor market. Prior to the introduction of this model, labor supply decisions were regarded as virtually irrelevant for this level of analysis, as it was assumed that aggregate labor supply was not determined by the factors which drive individual labor supply (Prescott and Wallenius 2011).

In the next section, I provide a brief presentation of a multi-period life-cycle model. Although a more realistic model would include multi-sectors, households, firms, government, and, perhaps, banking; I will limit my theoretical considerations to household and firm sectors. The main goal in this case is to provide a basis for deriving an empirically testable labor supply function for the current analysis. The model presented here shares certain characteristics with the L-R model, yet differs in some ways.

\subsection{Household behavior}

In an overlapping generation setting, each representative household lives up to a certain date T. In each period, the household which has reached $\mathrm{T}$ dies out and a newborn enters. The households derive their utility from consumption and leisure, which can be traded not only within, but also across periods.

For the sake of simplicity, I first consider the household as a single representative agent in the economy which does not correspond to the multi-generational agents in the OLG setting. In other words, the household behavior presented here is only comparable with aggregate time series analyses; e.g. Lucas and Rapping (1969) and Alogoskoufis (1987). The purpose of simplifying the model in this way is to derive the theoretical predictions of labor supply responses to wages. A more general model for multi-generational agents will be presented in the empirical estimation. For the single representative agent in the economy, the implicit lifetime utility function may be expressed as,

$$
U=\frac{1}{1-1 / \gamma} \sum_{t=0}^{T} \frac{1}{(1+\delta)^{t}} u_{t}\left(c_{t}, l_{t}\right)^{1-1 / \gamma}
$$

where, $t$ is age/time, $\delta$ is the rate of time preference, $\gamma$ is the inter-temporal elasticity of substitution, and $c$ and $l$ denote consumption and leisure, respectively. 
Assuming there is no income and payroll tax or any kind of social benefits, the household budget constraint is merely a function of current and future discounted assets and labor income, with the requirement that lifetime consumption does not exceed the earnings at the present value. The budget constraint can therefore be written as:

$$
a_{t}+\sum_{t=0}^{T} \prod_{t=0}^{T}\left(1+r_{t}\right)^{-1}\left[a_{t} r_{t}+w_{t}\left(1-l_{t}\right)\right] \geq \sum_{t=0}^{T} \prod_{t=0}^{T}\left(1+r_{t}\right)^{-1} c_{t}
$$

where, $c, l, r$ and $a$ are consumption, leisure, interest rate, and assets; respectively. $w$ is the per worker annual wage.

It is important to note that the value of $l$ is assumed to be $l \in[0,1]$, and reflects the age- or time-varying fraction of the total labor endowment allocated to leisure. Accordingly, $1-l$ is the fraction of the total labor endowment devoted to work. In general, for an unemployed person, $l=1$; whereas for a full-time worker, $l=0$, and any value between zero and one refers to the intensive margin of labor supply. As was argued by Alogoskoufis (1987), it may be assumed such a theoretical model is not suitable for modeling the extensive margin. To conduct the analysis using aggregate data, it is necessary to use a continuous variable which is in line with the work-leisure choice by a single representative agent. This issue will be discussed in greater detail later in the paper.

The preferences in (1) are further restricted by assuming that the implicit utility function is time-separable and in the nested constant elasticity of substitution form. This gives the annual utility function,

$$
u_{t}\left(c_{t}, l_{t}\right)=\left(c_{t}^{1-1 / \rho}+\alpha l_{t}^{1-1 / \rho}\right)^{\frac{1}{1-1 / \rho}}
$$

where, $\alpha$ and $\rho$ are the parameters of intensity for leisure and intra-temporal elasticity, respectively.

Each household maximizes its lifetime utility (1) subject to a lifetime budget constraint (2). At each age, a household solves a dynamic optimization problem, and derives its consumption and leisure. The economy is closed (i.e. it is not subject to international trade, capital flows, or migration) and both the labor market and the capital market are perfectly competitive. In addition, the household is assumed to have no bequest motive. Substituting (3) into (1), the Hamiltonian for each representative household may be expressed as:

$$
H_{t}=\frac{1}{(1+\delta)^{t}} \frac{1}{1-1 / \gamma}\left(c_{t}^{1-1 / \rho}+\alpha l_{t}^{1-1 / \rho}\right)^{\frac{1-1 / \gamma}{1-1 / \rho}}+\lambda_{t}\left[a_{t} r_{t}+w_{t}\left(1-l_{t}\right)-c_{t}\right]
$$

where, $\delta, \alpha, \gamma, \rho$ are the parameters of time preference, leisure intensity, intertemporal elasticity, and intra-temporal elasticity; respectively. Subscripts $t$ denote age/time. Let $c, l, r$, and $a$ be consumption, leisure, interest rate, and assets; respectively. $\lambda$ is the costate variable which can be interpreted as the marginal value of a unit change in the budget constraint. $w$ is the annual per worker wage rate. 
Maximizing (4) with respect to $c_{t}$ and $l_{t}$, respectively, yields the following two first-order conditions:

$$
\begin{gathered}
\lambda_{t}=(1+\delta)^{t}\left(c_{t}^{1-1 / \rho}+\alpha l_{t}^{1-1 / \rho}\right)^{\frac{1 / \rho-1 / \gamma}{1-1 / \rho}} c_{t}^{-1 / \rho} \\
\lambda_{t} w_{t}=(1+\delta)^{t}\left(c_{t}^{1-1 / \rho}+\alpha l_{t}^{1-1 / \rho}\right)^{\frac{1 / \rho-1 / \gamma}{1-1 / \rho}} \alpha l_{t}^{-1 / \rho}
\end{gathered}
$$

Combining the two first-order conditions yields (7), an expression for the intratemporal effect of wage change on consumption and leisure or labor supply. The sign of the parameter $\rho$ is hard to determine a priori due to the ambiguous effects of wage increases on the labor supply, as discussed in the preceding section. If $\rho$ is positive, an increase in wages would lower the leisure-consumption ratio, and would therefore imply an increase in the labor supply; that is, the substitution effect dominates. Conversely, a negative sign of $\rho$ implies a positive relationship between the changes in the wage rate and the leisure-consumption ratio, and thus a reduction in the labor supply, i.e. the income effect dominates.

$$
l_{t}=\left(\frac{w_{t}}{\alpha}\right)^{-\rho} c_{t}
$$

The change of the shadow value, $\lambda_{t}$, with respect to time/age equals the negative first-order condition of the Hamiltonian with respect to assets:

$$
\frac{\partial \lambda_{t}}{\partial t}=-\frac{\partial H_{t}}{\partial a_{t}}
$$

Therefore,

$$
\lambda_{t}-\lambda_{t-1}=-\lambda_{t} r_{t}
$$

Re-writing the previous equation, we get

$$
\frac{\lambda_{t}}{\lambda_{t-1}}=\frac{1}{1+r_{t}}
$$

Substituting (7) into (5), we get an expression for the shadow price $\lambda_{t}$ represented by consumption and divided by $\lambda_{t-1}$, we get,

$$
\frac{\lambda_{t}}{\lambda_{t-1}}=(1+\delta)^{-1}\left(\frac{c_{t}}{c_{t-1}}\right)^{-1 / \gamma}\left(\frac{1+\alpha^{\rho} w_{t}^{1-\rho}}{1+\alpha^{\rho} w_{t-1}^{1-\rho}}\right)^{\frac{1 / \rho-1 / \gamma}{1-1 / \rho}}
$$

Equating (10) and (11), we get two Euler equations for both consumption and leisure. Of these equations, only the latter will be used to derive the labor supply function in the following section. 


\subsection{Labor supply function}

As was previously mentioned, for a single household, $l$ reflects the fraction of the total labor endowment allocated to leisure; thus $1-l$ is equivalent to the fraction of total labor endowment spent in market work. This continuous variable corresponds to the intensive margin of the labor supply for the household.

In a macroeconomic context, it is necessary to ensure that the measured labor supply is comparable to that in the theoretical model. The measured labor supply has varied across previous empirical studies, and this lack of consistency has resulted in inconsistent evidence. As was discussed above, most of the variation in total man hours comes from employment variation, not from hours worked per head (Coleman 1984). In addition, this paper stresses the effect of wages on the individual labor supply decision at the extensive margin. Hence, I use the number of employed individuals instead of the total man hours as a measurement of labor supply in the aggregate economy.

Furthermore, to make the aggregate measure of labor supply consistent with the theoretical model, I use the employment rate as a proxy for the work-leisure choice by a single representative agent. This is because $l$ takes on the value between zero and one, as does the employment rate.

Let $e_{t}$ be the time-/age-varying employment rate, which is assumed to be equivalent to a fraction of the total labor endowment allocated to market work by a single representative household. Accordingly, the leisure variable for a single household in the aggregate economic context becomes the fraction of the population who are unemployed; thus, the aggregate version of leisure can be expressed by $l_{t}=1-e_{t}$. Hence, the dynamic change in leisure at the macro level can be written in the form:

$$
\frac{1-e_{t}}{1-e_{t-1}}=\left(\frac{1+r_{t}}{1+\delta}\right)^{\gamma}\left(\frac{1+\alpha^{\rho} w_{t}^{1-\rho}}{1+\alpha^{\rho} w_{t-1}^{1-\rho}}\right)^{\frac{\rho-\gamma}{1-\rho}}\left(\frac{w_{t}}{w_{t-1}}\right)^{-\rho}
$$

Taking the logarithm of (12), and using the first-order Taylor approximation for $\ln \left(1-e_{t}\right)$ and $\ln \left(1+\alpha^{\rho} w_{t}^{1-\rho}\right)$, a linear labor supply function may be written:

$$
\ln \left(e_{t}\right)=\ln \left(e_{t-1}\right)-\left(\frac{1-\bar{e}}{\bar{e}}\right) \gamma \ln \left(1+r_{t}\right)+\left(\frac{1-\bar{e}}{\bar{e}}\right) \gamma\left(\frac{\rho+\alpha^{\rho} \gamma}{\gamma+\alpha^{\rho} \gamma}\right) \ln \left(\frac{w_{t}}{w_{t-1}}\right)+\tau
$$

where, $\bar{e}$ is the parameter in the Taylor approximation for $\ln \left(1-e_{t}\right)$, which can be interpreted as a constant value of labor supply in steady state. $\tau$ equals $\left(\frac{1-\bar{e}}{\bar{e}}\right) \gamma \ln (1+$ $\delta)$, which will be captured by a time trend in the empirical estimation.

If the interest rate $r$ and the wage rate $w$ in (13) are adjusted for inflation, the model is similar to the L-R model. The only difference is that Lucas and Rapping deleted the interest rate, and therefore explicitly examined the effects of inflation on labor supply, whereas I implicitly assume that both the interest rate and the price will be governed by a single parameter, and thus have the same effect as non-labor income on the labor supply. For the model estimation, which will be discussed in 
more detail in the next section, $r$ is deflated by the annual percentage change in the price index, and $w$ is adjusted at a constant price level.

The advantage of estimating a labor supply function in the form of (13) is that it allows me to disentangle the inter-temporal and the intra-temporal responses to wage change. As was discussed earlier, such a distinction is important for a lifecycle labor supply analysis, as a wage change can be characterized by an anticipated move along the evolutionary wage path, and/or by an unanticipated wage shift. If we simply regressed the measured labor supply on wage rates, the estimated parameter would confound the two types of response. To make this point more explicitly, let $\beta_{1}$ represent $\left(\frac{1-\bar{e}}{\bar{e}}\right) \gamma$ and $\beta_{2}$ equal $\left(\frac{1-\bar{e}}{\bar{e}}\right) \gamma\left(\frac{\rho+\alpha^{\rho} \gamma}{\gamma+\alpha^{\rho} \gamma}\right)$, (13) can therefore be rewritten as:

$$
\ln \left(e_{t}\right)=\ln \left(e_{t-1}\right)-\beta_{1} \ln \left(1+r_{t}\right)+\beta_{2} \ln \left(\frac{w_{t}}{w_{t-1}}\right)+\tau
$$

If we merely estimate the model with only the wage rate, and not with the interest rate, the single parameter $\beta_{2}$ captures both the inter-temporal and the intra-temporal responses, making the distinct effects indistinguishable. When both the interest and the wage rates are included as explanatory variables (as in the form of (14)), the two elasticities, $\beta_{1}$ and $\beta_{2}$, can be used to identify the relative magnitude of the two types of responses.

\subsection{Aggregate demand for labor}

To estimate the labor supply function, such as (14), it is also necessary to derive rational expectations regarding wages. This involves specifying a model for the firm sector to derive the labor demand function. Following Lucas and Rapping (1969), I assume that the firm sector is a single production sector relying on labor and capital and behaving competitively. The production function is assumed to be in the form of constant elasticity of substitution with constant returns to scale, which can be written as:

$$
G_{t}=\left[a N_{t}^{-b}+(1-a) K_{t}^{-b}\right]^{-1 / b}
$$

where, $G, N, K$ are real output, unit of labor, and capital inputs at time $t$. $a$ measures the intensity of labor in production. $1 /(1+b)$ is the elasticity of substitution, which reflects the percentage change in the capital-labor ratio as a response to the percentage change in the ratio of the wage rate to the interest rate.

Given that the firm sector seeks to maximize profit under competition, the wage rate is the marginal product of labor. Thus, the rate can be derived by differentiating the real output with respect to the number of labor inputs in (15),

$$
w_{t}=\frac{\partial G_{t}}{\partial N_{t}}=a\left(\frac{G_{t}}{N_{t}}\right)^{1+b}
$$

Following Lucas and Rapping (1969), by postulating the logarithm on (16), rearranging the terms, and assuming that the labor and the real output follow an 
order one autoregressive process, the marginal labor productivity condition may be written as:

$$
\ln \left(\frac{N_{t}}{G_{t}}\right)=\pi_{0}-\pi_{1} \ln \left(w_{t}\right)+\pi_{2} \ln \left(\frac{G_{t}}{G_{t-1}}\right)+\pi_{3} \ln \left(\frac{N_{t-1}}{G_{t-1}}\right)
$$

Rearranging the terms in (17), the aggregate demand for labor $\left(N_{t}\right)$ can be expressed by the following function:

$$
\ln \left(N_{t}\right)=\pi_{0}-\pi_{1} \ln \left(w_{t}\right)+\pi_{2} \ln \left(\frac{G_{t}}{G_{t-1}}\right)+\pi_{3} \ln \left(\frac{N_{t-1}}{G_{t-1}}\right)+\ln \left(G_{t}\right)
$$

If we assume that the number of employed persons reflects the actual demand for labor, then $N_{t}=e_{t} \times P_{t}$, where, $P_{t}$ is the total population. Hence, (18) can be re-written as:

$$
\ln \left(e_{t}\right)=\pi_{0}-\pi_{1} \ln \left(w_{t}\right)+\pi_{2} \ln \left(\frac{G_{t}}{G_{t-1}}\right)+\pi_{3} \ln \left(\frac{N_{t-1}}{G_{t-1}}\right)+\ln \left(\frac{G_{t}}{P_{t}}\right)
$$

\subsection{Reduced form for real wage}

If we assume that the labor market clears at each period and that the demand for the number of workers equals the supply of the number of workers, the reduced form of the equation for wages can be derived by equating (14) to (19), that is:

$$
\begin{aligned}
\ln \left(w_{t}\right)= & \phi_{1}+\phi_{2} \ln \left(e_{t-1}\right)-\phi_{3} \ln \left(1+r_{t}\right)+\phi_{4} \ln \left(w_{t-1}\right) \\
& +\phi_{5} \ln \left(\frac{G_{t}}{G_{t-1}}\right)+\phi_{6} \ln \left(\frac{N_{t-1}}{G_{t-1}}\right)+\phi_{7} \ln \left(\frac{G_{t}}{P_{t}}\right)+\tau+u_{t}
\end{aligned}
$$

\subsection{Theoretical prediction of model parameters}

The preceding theoretical discussion of real wages and the labor supply generates two main predictions. First, the sign of the intra-temporal elasticity of labor supply w.r.t. wages can be either positive or negative, depending on whether income or substitution effects dominate. Second, the sign of the inter-temporal elasticity of labor supply w.r.t. wages can only be positive, as this is the labor supply response to the evolutionary wage rate, which is known to the household; i.e. there are only substitution effects.

There is no theoretical prediction of the relative magnitude of inter-temporal and intra-temporal elasticities. Hence, a statistical inference for the two parameter estimates will be made. In order to quantify the relative magnitude of the intertemporal and the intra-temporal responses, I assume that $\alpha=1$, household's utility 
weight on leisure is equal to that of consumption. ${ }^{4}$ Thus, the relative magnitude can be written as $\frac{\rho}{\gamma}=\frac{2 \beta_{2}}{\beta_{1}}-1$. Given this, the hypotheses are as follows:

Hypothesis 1: If $\frac{\beta_{2}}{\beta_{1}}>1$, the substitution effect dominates within the period, and the intra-temporal elasticity outweighs the inter-temporal elasticity of the labor supply w.r.t. the wage increase; i.e. $\frac{\rho}{\gamma}>1$.

Hypothesis 2: If $\frac{1}{2}<\frac{\beta_{2}}{\beta_{1}}<1$, the substitution effect dominates within the period, but the intra-temporal elasticity is outweighed by the inter-temporal elasticity of the labor supply w.r.t. the wage increase; i.e. $0<\frac{\rho}{\gamma}<1$.

Hypothesis 3: If $0<\frac{\beta_{2}}{\beta_{1}}<\frac{1}{2}$, the income effect dominates within the period, but the intra-temporal elasticity is outweighed by the inter-temporal elasticity of the labor supply w.r.t. the wage increase; i.e. $-1<\frac{\rho}{\gamma}<0$.

Hypothesis 4: If $\frac{\beta_{2}}{\beta_{1}}<0$, the income effect dominates within the period, and the intratemporal elasticity outweighs the inter-temporal elasticity of the labor supply w.r.t. the wage increase; i.e. $\frac{\rho}{\gamma}<-1$.

Hypothesis 5: If $\frac{\beta_{2}}{\beta_{1}}=1 ;$ i.e. $\beta_{2}=\beta_{1}$, the intra-temporal elasticity equals the intertemporal elasticity of the labor supply w.r.t. the wage increase; i.e, $\frac{\rho}{\gamma}=1$.

\subsection{Empirical evidence of model parameters}

Table 1 summarizes the model estimates from Lucas and Rapping (1969) and Alogoskoufis (1987), both of which are based on the U.S. aggregate time series data. The first column shows the estimates for the reduced form for the wage equation corresponding to (20). The coefficients in the second to the fourth columns are for the labor supply functions similar to (14). Notably, the estimated impact of wages on labor supply is larger in Lucas and Rapping (1969) than in Alogoskoufis (1987). This partly due to the differences in the measurements of labor supply, as the former used aggregate total man hours, while the latter used employment rates.

\footnotetext{
4 The $\alpha$ parameter represents the utility weight the household attaches to leisure relative to consumption. If $\alpha$ is greater than one, the household prefers leisure to consumption, and therefore supplies less labor. Conversely, if $\alpha$ is smaller than one but greater than zero, the household prefers consumption to leisure, and therefore supplies more labor. Two special cases are when $\alpha$ equals zero and one. The former case refers to the fixed labor supply assumption, in which a household is expected to choose no leisure; thus, it reduces to a constant relative risk aversion utility function (CRRA). The latter case refers to the assumption of an equal utility weight on leisure and consumption; that is, the household is expected to be indifferent about whether it consumes a unit of goods or a unit of leisure, ceteris paribus. As can be seen in (7), if $\alpha$ equals one, the leisure-consumption choice is only influenced by the wage rates and governed by the parameter of intra-temporal elasticity.
} 
Table 1:

Evidence from previous empirical studies

\begin{tabular}{|c|c|c|c|c|}
\hline \multirow[b]{2}{*}{ Variables } & \multicolumn{2}{|c|}{ Lucas and Rapping (1969) } & \multicolumn{2}{|c|}{ Alogoskoufis (1987) } \\
\hline & $\begin{array}{l}\text { Reduced form } \\
\qquad \ln \left(w_{t}\right)\end{array}$ & $\begin{array}{c}\text { Man-hours } \\
\quad \ln \left(h_{t}\right)\end{array}$ & $\begin{array}{c}\text { Employment rate } \\
\ln \left(e_{t}\right)\end{array}$ & $\begin{array}{c}\text { Employment rate } \\
\ln \left(e_{t}\right)\end{array}$ \\
\hline $\ln \left(w_{t}\right)$ & $\mathrm{x}$ & 1.40 & 0.90 & 0.91 \\
\hline $\ln \left(w_{t-1}\right)$ & 0.44 & -1.39 & -0.85 & -0.91 \\
\hline $\ln \left(1+r_{t}\right)$ & $\mathrm{x}$ & $\mathrm{x}$ & 0.34 & 0.35 \\
\hline $\ln \left(h_{t-1}\right)$ & -1.15 & 0.64 & $\mathrm{x}$ & $\mathrm{x}$ \\
\hline $\ln \left(e_{t-1}\right)$ & $\mathrm{x}$ & $\mathrm{x}$ & 1.01 & 1.00 \\
\hline $\ln \left(\frac{G_{t}}{G_{t-1}}\right)$ & -1.22 & $\mathrm{x}$ & $\mathrm{x}$ & $\mathrm{x}$ \\
\hline $\ln \left(\frac{N_{t-1}}{G_{t-1}}\right)$ & 1.24 & $\mathrm{x}$ & $\mathrm{x}$ & $\mathrm{x}$ \\
\hline $\ln \left(\frac{G_{t}}{P_{t}}\right)$ & 1.25 & $\mathrm{x}$ & $\mathrm{x}$ & $\mathrm{x}$ \\
\hline Parameter constraints & $\mathrm{x}$ & $\mathrm{x}$ & $\mathrm{x}$ & $\begin{array}{c}\ln \left(w_{t}\right)=\ln \left(w_{t-1}\right) \\
\ln \left(e_{t-1}\right)=1\end{array}$ \\
\hline
\end{tabular}

It is noteworthy that the difference between the two models in Alogoskoufis (1987), which used the employment rate as a dependent variable, is that one of the models imposed two restrictions on the parameters: the coefficients on the current and the lagged wages were equal to each other, and the lagged employment rate was constrained to one. This restriction allowed the author to compare the relative magnitude of the inter- and intra-temporal elasticity of substitution. Based on their parameter estimates, the ratio $\frac{\rho}{\gamma}$ is 4.2 , which suggests that the static elasticity of substitution between consumption and leisure is more than four times greater than the inter-temporal elasticity of substitution.

The two empirical studies reviewed here suggest that the short-run labor supply elasticity with respect to wages is positive, and is around unity. Lucas and Rapping (1969) obtained large estimates, 1.4; and further claimed that the Keynesian type assumption of elastic short-run labor supply is valid. Alogoskoufis (1987), on the other hand, showed that the intra-temporal elasticity of substitution outweighs the inter-temporal elasticity.

\section{Data and methods}

\subsection{National transfer accounts Sweden 1985-2003}

The age profile of labor income in the National Transfer Accounts (NTA) is a comprehensive measure of the age differentials in the market value of total labor 
supply, weighted by all of the members of a population in a particular age group (Lee and Ogawa 2011). By definition, NTA labor income includes employees' labor earnings, self-employed labor income, fringe benefits, and payroll tax contributed by employers. The NTA time series for Sweden includes repeated cross-sectional age profiles over the period 1985-2003. For each year, the relationship between the total and the age-specific labor income at the aggregate level can be expressed as:

$$
Y_{t}=\sum_{x} Y_{x, t}=\sum_{x} w_{x, t} \times E_{x, t}
$$

where, $x$ and $t$ denote age and time, respectively. Let $Y$ be the aggregate annual labor income, $E$ be the number of employed person in the economy, and $w$ be de facto annual wage per employee.

Equation (21) implies that the NTA age-specific labor income is a product of the de facto annual wages for those who are employed and the number of employees in the same age group. That is:

$$
Y_{x, t}=w_{x, t} \times E_{x, t}=w_{x, t} \times \frac{E_{x, t}}{P_{x, t}} \times P_{x, t}
$$

where, $P_{x, t}$ is the age-specific population at time $t$.

It is evident from (22) that the aggregate age-specific labor income $\left(Y_{x, t}\right)$ based on the NTA definition confounds the effects of the market wage rate $\left(w_{x, t}\right)$, the employment rate $\left(\frac{E_{x, t}}{P_{x, t}}\right)$, and the population size in each age group $P_{x, t}$. Dividing (22) by age-specific population on both sides yields per capita age-specific labor income as a function of the wage rate times the employment rate,

$$
y_{x, t}=w_{x, t} \times \frac{E_{x, t}}{P_{x, t}}=w_{x, t} \times e_{x, t}
$$

where, $e_{x, t}$ denotes the employment rate for each age group at time $t$.

From (23), it is obvious that the difference between the NTA labor income and the conventional wage rate is affected by the employment rate. They would be equivalent if, and only if, the condition of full employment is satisfied; that is, if the equilibrium wage rate is at the market clearing level of no voluntary and involuntary unemployment. In this regard, the NTA provides a framework which is consistent with general equilibrium theory by linking population structure and aggregate national income. But since the empirical data suggest that unemployment always exists, the NTA labor income should not be analyzed in isolation. To gain an understanding of the dynamic age profiles of labor income over time, it is necessary to look at the variation in these decomposed components; namely, wage and employment rates.

The NTA time series for Sweden provides information on per capita age-specific labor income for each year between 1985 and 2003; i.e. $y_{x, t}$ in (23). The wage rate per employed person, $w_{x, t}$, is then calculated by dividing $y_{x, t}$ by the employment 
rate, $e_{x, t}$ for each age and time. Unfortunately, the employment rates provided by Statistics Sweden are aggregated by the following age groups: 16-19, 20-24, 25$34,35-44,45-54,55-59$, and 60-64. Hence, the derived wage rates are computed in accordance with these age groups. All of the wage rates are adjusted to the price level in the year 1985. The price information was obtained from Statistics Sweden. Furthermore, I use a series of short-run annual yields as a proxy for asset return $r$ in (14), which are extracted from the Annual Swedish stock prices and returns, and from the bond yields for 1856-2006 published by the Swedish Riksbank.

\subsection{Age profiles over time}

To examine the changing age distribution of work compensation and employment rates overtime, the data are fitted by the Lee-Carter method (Lee and Carter 1992). This approach allows me to capture the changing shape of the life-cycle wage rates and the labor supply, and to investigate the age-specific responses to the overall trends of the two variables.

There have been dramatic social and economic changes over the investigation period: the economic crisis of 1990-1993, the passage of new legislation on the pension system in 1994 which mandated a move toward a notional defined contribution model, and the implementation of the legislation in the early 2000s. To account for the impact of changing macroeconomic and institutional conditions, the time-varying age profiles are fitted for four sub-periods: 1985-89, 1990-93, 199499, and 2000-03.

\subsection{Estimating labor supply function}

\subsubsection{Population composition index}

The yearly variation in the number of employed persons, such as $E$ in (22), may be influenced by changes in the labor force composition over time, such as the timevarying distributions of age, gender, and education, etc. If such compositional effects exist, the estimated elasticity of labor supply with respect to wage may be biased. Thus, following Lucas and Rapping (1969), the annual number of employed person $E$ is deflated by the population compositional index $M$, which may be written as:

$$
M_{t}=\frac{\sum_{i=1}^{n}\left(\frac{E_{0, i}}{P_{0, i}}\right) \times P_{t, i}}{E_{0}}
$$


where, subscript $t$ and $i$ is time and each of the population subgroups, ${ }^{5} . E$ and $P$ are the number of employed person and the population. Subscript zero refers to the initial time period.

As Lucas and Rapping (1969) argued, this index generates a counterfactual variable which reflects the relative increase in the labor force which would have occurred solely due to the variation in the composition of the population, holding the group-specific employment rates constant. Therefore, deflating $E$ by $M$ will eliminate the impact of population compositional changes on the number of employed persons.

\subsubsection{Aggregate time-series estimation}

As was argued above, since $E$ needs to be deflated by $M$, the employment and the wage rates must follow the same procedure. Thus, (14) may be rewritten as:

$$
\ln \left(e_{t} / M_{t}\right)=\ln \left(e_{t-1} / M_{t-1}\right)-\beta_{1} \ln \left(1+r_{t}\right)+\beta_{2} \ln \left(\frac{w_{t} / M_{t}}{w_{t-1} / M_{t-1}}\right)+\tau+\epsilon_{t}
$$

Accordingly, the reduced form equation for wage becomes:

$$
\begin{aligned}
\ln \left(w_{t}\right)= & \phi_{1}+\phi_{2} \ln \left(e_{t-1} / M_{t-1}\right)-\phi_{3} \ln \left(1+r_{t}\right)+\phi_{4} \ln \left(w_{t-1} / M_{t-1}\right) \\
& +\phi_{5} \ln \left(\frac{G_{t}}{G_{t-1}}\right)+\phi_{6} \ln \left(\frac{N_{t-1}}{G_{t-1}}\right)+\phi_{7} \ln \left(\frac{G_{t}}{P_{t} M_{t}}\right)+\tau+u_{t}
\end{aligned}
$$

The price and the interest rates are assumed to be exogenous to the household in this model, while the labor supply and the wage rates are assumed to be endogenous. Two-stage least squares (2SLS) is applied to estimate the elasticity of the labor supply with respect to wages, $\beta_{2}$ in (25). Equation (26) is estimated at the first stage to form the household's expectations regarding wages. The instrumental variables in the reduced-form equation are $\ln \left(\frac{G_{t}}{G_{t-1}}\right), \ln \left(\frac{N_{t-1}}{G_{t-1}}\right)$, and $\ln \left(\frac{G_{t}}{P_{t} M_{t}}\right)$. I use the annual gross domestic product (GDP), collected by Statistics Sweden, as a proxy for total output $G$. The series is deflated by a price index with the base year 1985 .

It is important to note that the variables $G, N, P$, and $M$ are assumed to be exogenous to wages. The theoretical model presented earlier assumes that wages are determined by the firm sector based on their total output $G$ and the demand for labor $N$. However, it could be argued that population size $P$ and population composition index $M$ are endogenous to wages, as fertility, mortality, and migration might be influenced by income. Nevertheless, following Lucas and Rapping (1969), they are treated as predetermined factors based on the argument that current demographic patterns, particularly for fertility and mortality, are the result of past decisions which

\footnotetext{
5 The subgroups are similar to Lucas and Rapping (1969). $i$ 's refer to 14 age-gender groups; that is, male and female groups for each of the age groups used by Statistics Sweden when reporting annual employment rates: 16-19, 20-24, 25-34, 35-44, 45-54, 55-59, and 60-64.
} 
depend partly on past wages. Furthermore, it might take decades for the impact of wages on demographic outcomes to become noticeable. Therefore, $P$ and $M$ are regarded as exogenous to current wages.

The interpretation of the three instruments in (26) is straightforward. $\ln \left(\frac{G_{t}}{G_{t-1}}\right)$ is the annual growth rate of the economy. $\ln \left(\frac{N_{t-1}}{G_{t-1}}\right)$ reflects the units of labor input for each unit of output; i.e. the marginal productivity condition for labor. $\ln \left(\frac{G_{t}}{P_{t} M_{t}}\right)$ is the GDP per capita deflated by the population composition index, or the counterfactual per capita output in an economy which is not driven by changes in the population composition.

Equation (25) is identical to the model estimated by Alogoskoufis (1987), presented in the last column in Table 1. This is a restricted model with two coefficient constraints which allow us to test hypotheses 1-5. A more general labor supply function, the unrestricted model in the form of (27), is also estimated and reported in the following section. This model is similar to the two models by Alogoskoufis (1987) presented in columns 2 and 3 in Table 1.

$$
\begin{aligned}
\ln \left(e_{t} / M_{t}\right)= & \theta_{0}+\theta_{1} \ln \left(e_{t-1} / M_{t-1}\right)-\theta_{2} \ln \left(1+r_{t}\right) \\
& +\theta_{3} \ln \left(w_{t} / M_{t}\right)-\theta_{4} \ln \left(w_{t-1} / M_{t-1}\right)+\tau+\epsilon_{t}
\end{aligned}
$$

It is important to stress that the estimation using (25), (27), and (26) corresponds to a single representative household. In the estimation, the wage and the employment rates are aggregated over all age groups. Thus, the estimated elasticity is consistent with the aforementioned theoretical model, and is comparable with the previous empirical evidence summarized in Table 1. For the age-specific analysis, model modifications are illustrated in the next section.

\subsubsection{Age-specific time-series estimation}

Before we can estimate the age-specific labor supply function, certain adjustments need to be made to make the model and the data compatible.

The NTA time series data are in the form of repeated cross-sections of agespecific labor income over time. Ideally, to ensure that the data reflect relatively realistic life-cycle dynamics, it would be beneficial to estimate the data using either an age-specific cohort perspective or a cohort-specific period perspective. However, given the aggregation of the employment rates into multi-year age groups and the limited time span of the data, such an analysis is not feasible. Presently, the only option is to pursue the analysis in an age-specific period setting. Although this strategy is inferior to conducting a synthetic cohort analysis, it is certainly preferable to conducting an aggregate time series analysis. As the estimated elasticities are distinguishable by age groups, this approach will provide us with greater insights into how the elasticity of the labor supply with respect to wages may differ at various stages of the life-cycle.

Given the age-specific period setting, equations (25),(26), and (27) are modified in the following way. Let $x$ be age and $t$ be calendar time, the estimation equation 
for age-specific labor supply be based on (25) is,

$$
\begin{aligned}
\ln \left(e_{x, t} / M_{t}\right)= & \ln \left(e_{x, t-1} / M_{t-1}\right)-\beta_{x, 1} \ln \left(1+r_{t}\right) \\
& +\beta_{x, 2} \ln \left(\frac{w_{x, t} / M_{t}}{w_{x, t-1} / M_{t-1}}\right)+\tau_{x}+\epsilon_{x, t}
\end{aligned}
$$

And the reduced-form equation for age-specific wages corresponding to (26) is,

$$
\begin{aligned}
\ln \left(w_{x, t}\right)= & \phi_{x, 1}+\phi_{x, 2} \ln \left(e_{x, t-1} / M_{t-1}\right)-\phi_{x, 3} \ln \left(1+r_{t}\right)+\phi_{x, 4} \ln \left(w_{x, t-1}\right) \\
& +\phi_{x, 5} \ln \left(\frac{G_{t}}{G_{t-1}}\right)+\phi_{x, 6} \ln \left(\frac{N_{t-1}}{G_{t-1}}\right)+\phi_{x, 7} \ln \left(\frac{G_{t}}{P_{t} M_{t}}\right)+\tau_{x}+u_{x, t}
\end{aligned}
$$

For the unrestricted model, (27), the corresponding age-specific equation may be written as,

$$
\begin{aligned}
\ln \left(e_{x, t} / M_{t}\right)= & \theta_{x, 0}+\theta_{x, 1} \ln \left(e_{x, t-1} / M_{t-1}\right)-\theta_{x, 2} \ln \left(1+r_{t}\right) \\
& +\theta_{x, 3} \ln \left(w_{x, t} / M_{t}\right)-\theta_{x, 4} \ln \left(w_{x, t-1} / M_{t-1}\right)+\tau_{x}+\epsilon_{x, t}
\end{aligned}
$$

The main difference between the aggregate and the age-specific time series equations is that the two endogenous variables, employment rates and wages, are disaggregated into age groups. It must be noted that the elasticity estimated by such a specification does not reflect the actual life-cycle behavior, as the age-specific variables vary only over time, not by age. To interpret the parameter as an intertemporal elasticity of substitution, it is necessary to assume that a change in the age-specific variable over time (between $x, t$ and $x, t+1$ ) approximately equals a change across the age-period (between $x, t$ and $x+1, t+1$ ).

All of the variables assumed to be exogenous $(M, r, G, N, P)$ are measured at the aggregate level. This assumes that the households at the different ages are exposed to identical macroeconomic conditions at each time period, but are affected differently.

Parameters in the reduced-form equation (29) shall be interpreted as the agespecific effect of aggregate economic changes on wages. In turn, this forms the wage expectation for each age group, and relates it to the age-specific employment rates. The age-specific elasticity estimates are not equivalent to the theoretical model presented earlier; nor are they directly comparable with the estimates in Table 1. Nonetheless, decomposed elasticities by age are useful for addressing the question of whether the labor supply response to wages differs over the life-cycle. More importantly, is it necessary to calibrate an array of life-cycle or age-specific elasticities in the OLG model?

As was mentioned above, an age-specific period setting might not be ideal for studying life-cycle behavior, as year-to-year variation may only approximate behavioral modification over the life-cycle. Since the data are treated as if they were in the age-specific period rather than in the cohort-specific period setting, the parameters $\left(\beta_{x, 2}\right.$ and $\theta_{x, 3}$ in (28) and (30), respectively) shall be interpreted as a vector of 'quasi' life-cycle labor supply elasticities. 


\section{Figure 1:}

Fitted age profiles of per capita real wage (log scale) by sub-periods using the Lee-Carter method

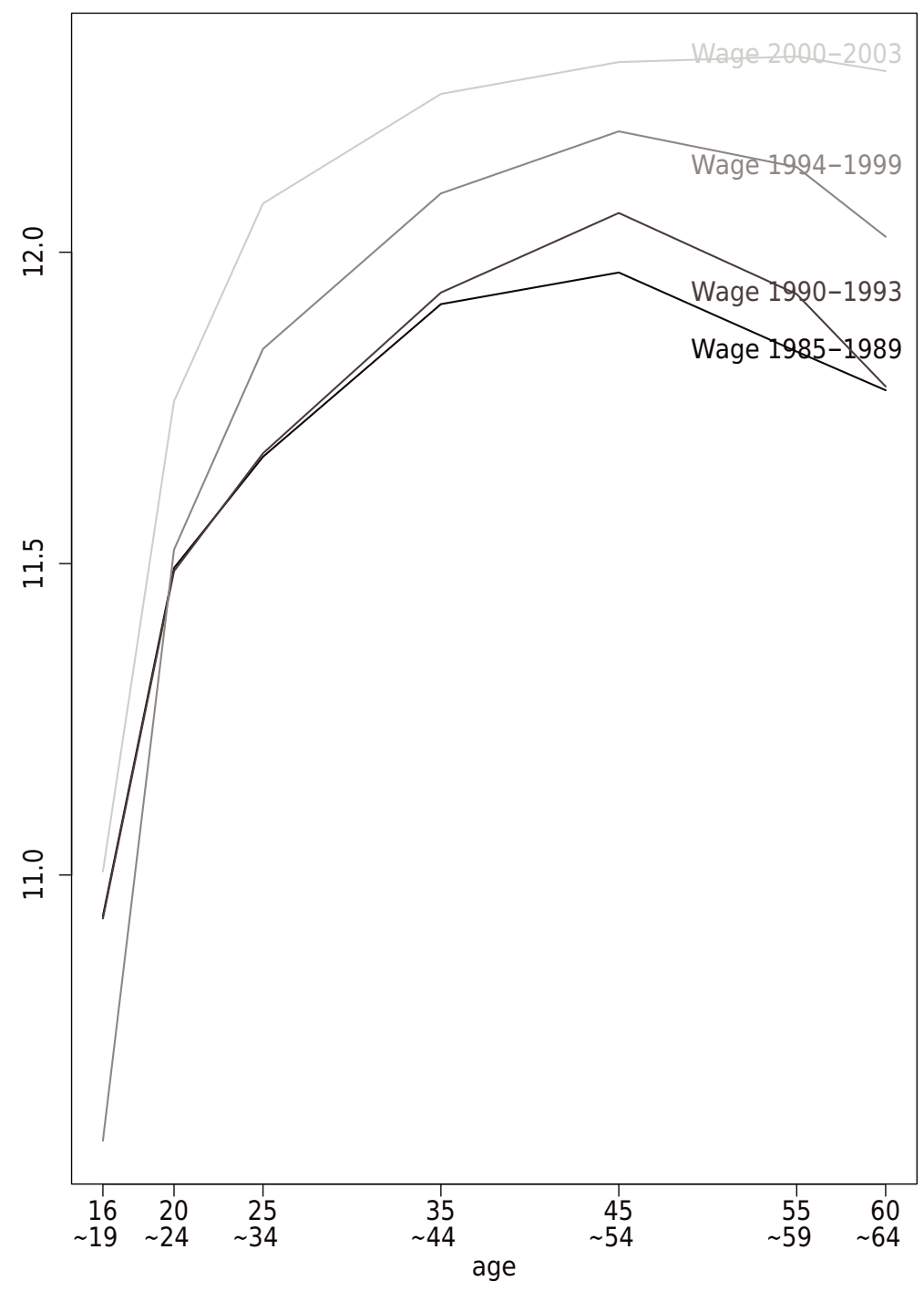

\section{Results and discussion}

\subsection{Some descriptive results}

Figures 1 and 2 illustrate the predicted average age profiles of real wage and employment rates by sub-periods, respectively, using the Lee-Carter method. In general, the wage rate is consistently higher for older workers than for younger workers, which is in line with the predictions of the theories reviewed in the previous section. However, the pattern appears to be shifting toward older ages over time.

Until 1999, the age-earning profiles are characterized by a steep increase from the labor market entry age, peaking at ages 45-54, and gradually declining thereafter. This pattern is in line with Skirbekk's summary of the OECD data, which indicates 
Figure 2:

Fitted age profiles of labor force participation rate (log scale) by sub-periods using the Lee-Carter method

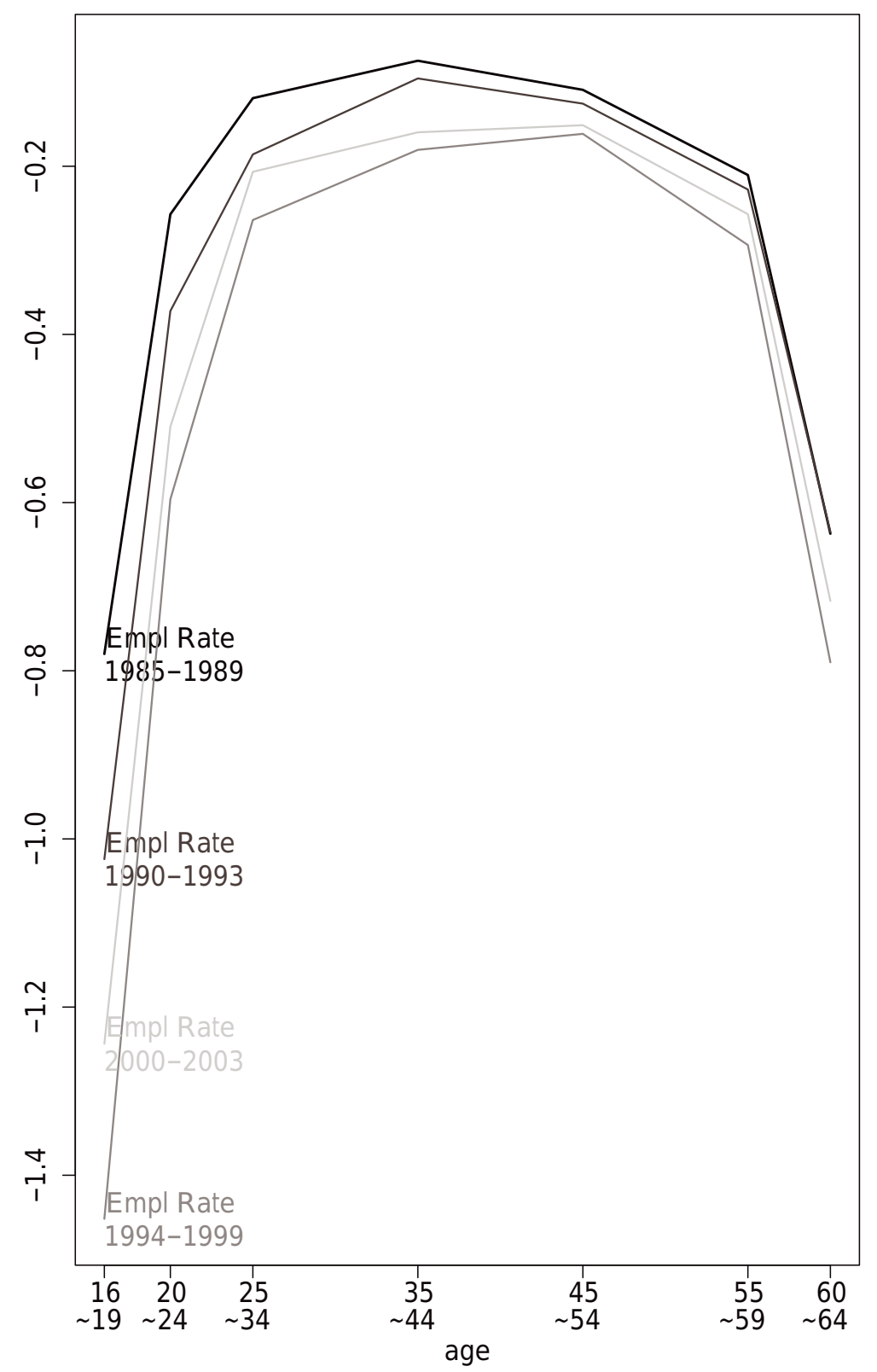

that workers' wages peak at ages 45-54 in 17 out of the 19 OECD countries (Skirbekk 2003). ${ }^{6}$

However, in the 2000-2003 period this pattern changed. As the light gray line in Figure 1 illustrates, during this period wages peaked at ages 55-59, and earnings remained high through age 64 . These results are somewhat similar to the findings

6 These countries are Australia, Canada, Denmark, Finland, France, Germany, Ireland, Italy, Japan, Mexico, the Netherlands, New Zealand, Norway, Portugal, Sweden, Switzerland, and the U.S. 
Figure 3:

Comparison of fitted age-specific responsiveness in real wages and labor force participation 1985-2003

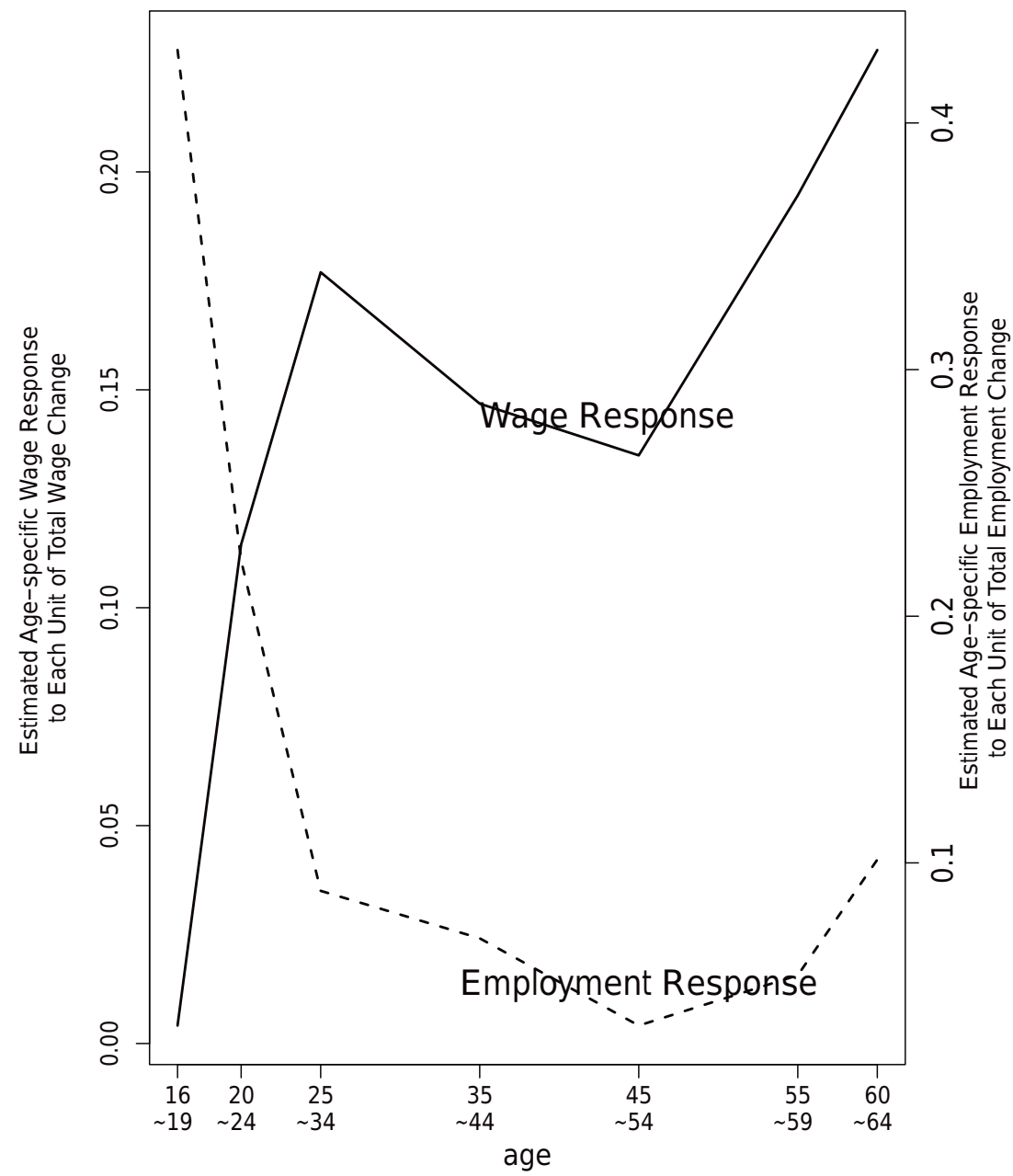

of Lee et al. (2011) for the U.S., which show that earnings among men have been increasing steadily with age. According to Lee et al. (2011), one of the explanations for this shift could be that younger workers no longer possess an educational advantage over older workers.

This shift may also be explained using the efficiency wage hypothesis or the shirking model. Alternatively, it may be attributed to factors such as the wageproductivity discrepancy, the nature of the optimal wage profile, the value placed on work experience, and the trade union preference given to older workers. All of these factors may contribute to the trend toward higher compensation levels for senior workers and lower wages for junior workers.

If we look at Figures 1 and 2 simultaneously, we can see that over the life-cycle both wages and employment appear to be hump-shaped. This is in line with the ISH prediction that wage and labor supply should be positively correlated; however, the rate of change for the two life-cycle series vary at different ages. From age 16 to age 34 , the employment rate grows at more or less the same pace as wages. But the 
employment curve flattens out between age 35 and 54, while the wage curve trends continuously upward.

The most striking feature is the divergence of employment and wages after age 54 . The decline in employment is too steep to be explained by decreasing wages. This divergence seems to be amplified over time, particularly for the most recent period (2000-03), in which employment drops considerably while wage rates flatten out between age 54 and 64. Taken together, this evidence implies that the ISH might not be able to fully explain the labor supply over the entire life-cycle, as it falls short in explaining the sharp decline in employment after age 54.

Figure 3 shows the relative age-specific contribution to the overall change in wages and employment over the period 1985-2003. If we look at the youngest and the oldest workers in this figure, it is evident that the wage and the labor supply responses are negatively associated. For workers aged 16-19, wage growth is nearly zero with respect to one unit of change in aggregate wage rate, whereas employment changed by more than 40 per cent for each unit of change in the aggregate employment rate. At the other extreme, workers aged 60-64 gained more than 20 per cent for each unit of increase in their overall wages, which is more than twice as high as their employment response.

\subsection{Estimated elasticities of the labor supply w.r.t. real wages}

\subsubsection{Aggregate estimates}

The estimates reported in Table 2 are comparable to those summarized in Table 1, as they are all obtained based on aggregate time series data and are equivalent to the labor supply of a single representative household.

The reduced form estimates presented in the first column in Table 2 have the same signs as those estimated by Lucas and Rapping (1969) (see Table 1, first column). The magnitude of the coefficients are, however, much larger than those reported by Lucas and Rapping (1969). I further applied the Sargan-Hansen test (See Overid sargan in Table 2) to verify the validity of the instruments. For all three instruments, I did not reject the null hypothesis that these instruments are valid, uncorrelated with the error term, and correctly excluded them from the labor supply estimation equation.

The second and third columns of Table 2 report the parameter estimates of the labor supply function (25) and (27), respectively. The estimated elasticity of the labor supply is 0.76 , which is not far from the elasticity reported by Alogoskoufis (1987) (See the last column of Table 1). The unrestricted elasticity (0.92) is the same as it is in the third column of Table 1. Both my estimates of labor supply elasticity and the estimates from Alogoskoufis (1987) are less than unity; however, the estimates reported in Lucas and Rapping (1969) are much larger. This might be partly due to the differences in the measurement of labor supply; i.e. by man hours or by the employment rate. 
Table 2:

Estimation of Aggregate time series data, reduced form (26), labor supply (25) and (27)

\begin{tabular}{|c|c|c|c|}
\hline Variables & $\begin{array}{c}(26) \\
\ln \left(w_{t}\right)\end{array}$ & $\begin{array}{c}(25) \\
\ln \left(e_{t} / M_{t}\right)\end{array}$ & $\begin{array}{c}(27) \\
\ln \left(e_{t} / M_{t}\right)\end{array}$ \\
\hline $\ln \left(w_{t} / M_{t}\right)$ & & $\begin{array}{c}0.759 * * \\
(0.299)\end{array}$ & $\begin{array}{c}0.916 \\
(0.645)\end{array}$ \\
\hline $\ln \left(w_{t-1} / M_{t-1}\right)$ & $\begin{array}{l}0.669 * \\
(0.362)\end{array}$ & $\begin{array}{c}-0.759 * * \\
(0.299)\end{array}$ & $\begin{array}{l}-0.424 \\
(0.695)\end{array}$ \\
\hline $\ln \left(1+r_{t}\right)$ & $\begin{array}{c}0.069 \\
(0.281)\end{array}$ & $\begin{array}{c}-0.555^{* * * *} \\
(0.115)\end{array}$ & $\begin{array}{l}-0.155 \\
(0.290)\end{array}$ \\
\hline $\ln \left(e_{t-1} / M_{t-1}\right)$ & $\begin{array}{l}-2.076 \\
(1.580)\end{array}$ & 1 & $\begin{array}{c}0.935 * * * \\
(0.240)\end{array}$ \\
\hline $\ln \left(G_{t} / G_{t-1}\right)$ & $\begin{array}{l}-1.813 \\
(1.639)\end{array}$ & & \\
\hline $\ln \left(N_{t-1} / G_{t-1}\right)$ & $\begin{array}{l}1.756 \\
(1.730)\end{array}$ & & \\
\hline $\ln \left(G_{t} / P_{t} M_{t}\right)$ & $\begin{array}{c}2.064 \\
(1.668)\end{array}$ & & \\
\hline$\tau$ & $\begin{array}{c}0.000 \\
(0.009)\end{array}$ & $\begin{array}{l}-0.001 \\
(0.001)\end{array}$ & $\begin{array}{c}-0.012 * * \\
(0.005)\end{array}$ \\
\hline Constant & $\begin{array}{c}-0.102 \\
(16.289)\end{array}$ & $\begin{array}{c}1.550 \\
(1.401)\end{array}$ & $\begin{array}{c}21.052 * * \\
(9.766)\end{array}$ \\
\hline Observations & 18 & 18 & 18 \\
\hline R-squared & 0.987 & & 0.937 \\
\hline F-test (p-value) & & 0.525 & \\
\hline$\rho / \gamma$ & & 1.732 & \\
\hline Overid sargan ( $p$-value) & & & 0.244 \\
\hline
\end{tabular}

Note: Standard errors in parentheses

$* * * \mathrm{p}<0.01, * * \mathrm{p}<0.05, * \mathrm{p}<0.1$

Overid: Sargan over-identification test.

F-test: equality test for hypothesis $5: H_{0}: \beta_{1}=\beta_{2}(\rho=\gamma)$

$\rho / \gamma$ : the relative magnitude of intra- to inter-temporal elasticity.

The time trend, $\tau$, captures factors which might shift over time. These factors are the steady state labor supply in the Taylor approximation $\frac{1-\bar{e}}{\bar{e}}$, the inter-temporal elasticity of substitution $\gamma$, and the rate of time preference $\ln (1+\delta)$. Since $\gamma$ and $\ln (1+\delta)$ are theoretically positive, the estimated negative time trend in both the restricted and the unrestricted models (See $\tau$ in the second and third column of Table 2) implies that the constant in the Taylor approximation or the steady-state labor supply follows a downward trend over time. Such a downward trend is in line with the pattern shown in Figure 2: i.e. a decrease in employment rates at all ages from the early 1990 s to the 2000 s. 
In terms of the relative magnitude of intra- and inter-temporal elasticity, the estimated $\frac{\rho}{\gamma}$ in Table 2 suggests that the intra-temporal outweighs the intertemporal elasticity of substitution, a finding which is similar to Alogoskoufis (1987). According to his coefficient estimates in the restricted model, column 3 in Table 1, the $\frac{\rho}{\gamma}$ is 4.2 . The estimate of this ratio in the present study is lower, or 1.7, which suggests that the static elasticity of substitution between consumption and leisure is 70 per cent greater than the inter-temporal elasticity of substitution; however, this inequality does not hold statistically. The F-test in Table 2 does not reject the equality test between $\rho$ and $\gamma$, which implies that the intra-temporal and the intertemporal elasticity of substitution are statistically the same, and confirms the validity of hypothesis 5 .

\subsubsection{Age-specific estimates}

The parameters by age-specific estimation vary across age groups in both the reduced form wage equation and the labor supply function. Table 3 reports the coefficients for the age-specific estimation reduced from the equation. The most striking feature is the disproportionate impact of macroeconomic conditions on wages across the different age groups. The annual rates of economic growth, the marginal productivity conditions for labor, and the population composition adjusted for GDP per capita all had much larger effects on wages for those under age 34 than for their older counterparts (see $\ln \left(G_{t} / G_{t-1}\right), \ln \left(N_{t-1} / G_{t-1}\right)$, and $\ln \left(G_{t} / P_{t} M_{t}\right)$ in the first three column of Table 3).

It is also important to note that the age-specific time trends $\left(\tau_{x}\right.$ in Table 3$)$ for the period 1985-2003 show that wages followed a downward trend for workers under the age of 34, and an upward trend for workers aged $45+$. This result is in line with the findings by Lee et al. (2011) for the U.S., which indicate that the earnings of older men have been rising more quickly than the earnings of younger men. It is important to stress that the wage rates are deflated by the population composition index; thus, the wage effects of macroeconomic variation and the longterm trend do not confound any impact from the age-gender distributional change in the population.

Table 4 reports the coefficient estimates of the unrestricted labor supply function corresponding to equation (30). From the first row in Table 4, we can see that the short-run labor supply elasticity with respect to real wages differs considerably across age groups. Individuals aged 16-24 appear to have had a relatively elastic supply schedule compared to older workers. Following the interpretation of this elasticity by Lucas and Rapping (1969), the Keynesian assumption of a relatively elastic short-run supply schedule is only confirmed for the workers aged 34 or younger.

The age groups 35-44 and 55-59 are the only groups whose labor supply elasticities (around 0.9) are close to the aggregate estimate in the third column of Table 2. This implies that the aggregate time series estimation does not capture 
Table 3:

Estimation of age-specific time-series data, reduced form Eq. (29)

\begin{tabular}{lccccccc}
\hline Variables & $\mathbf{1 6 - 1 9}$ & $\mathbf{2 0 - 2 4}$ & $\mathbf{2 5 - 3 4}$ & $\begin{array}{c}\mathbf{3 5 - 4 4} \\
\mathbf{l n}\left(\boldsymbol{w}_{x, t}\right)\end{array}$ & $\mathbf{4 5 - 5 4}$ & $\mathbf{5 5 - 5 9}$ & $\mathbf{6 0 - 6 4}$ \\
\hline $\ln \left(w_{x, t-1} / M_{t-1}\right)$ & -0.001 & $0.660^{* *}$ & 0.211 & 0.559 & 0.349 & 0.521 & $0.804^{*}$ \\
& $(0.365)$ & $(0.210)$ & $(0.283)$ & $(0.363)$ & $(0.338)$ & $(0.352)$ & $(0.391)$ \\
$\ln \left(1+r_{t}\right)$ & -0.497 & 0.244 & 0.425 & -0.106 & 0.096 & -0.003 & 0.306 \\
& $(1.719)$ & $(0.443)$ & $(0.258)$ & $(0.340)$ & $(0.304)$ & $(0.326)$ & $(0.606)$ \\
$\ln \left(e_{x, t-1} / M_{t-1}\right)$ & 3.197 & 0.424 & $2.647 * *$ & -1.236 & 0.874 & -0.660 & -0.329 \\
& $(1.988)$ & $(0.594)$ & $(1.037)$ & $(0.950)$ & $(1.786)$ & $(0.791)$ & $(0.577)$ \\
$\ln \left(G_{t} / G_{t-1}\right)$ & 12.604 & 1.237 & $2.825^{* *}$ & -0.563 & 0.472 & -0.090 & 0.281 \\
& $(9.421)$ & $(1.588)$ & $(0.948)$ & $(0.795)$ & $(0.787)$ & $(0.594)$ & $(0.860)$ \\
$\ln \left(N_{t-1} / G_{t-1}\right)$ & -11.428 & -1.723 & $-3.899 * *$ & 0.695 & -0.807 & 0.054 & 0.221 \\
& $(7.934)$ & $(1.648)$ & $(1.257)$ & $(0.972)$ & $(0.786)$ & $(1.057)$ & $(1.644)$ \\
$\ln \left(G_{t} / P_{t} M_{t}\right)$ & -11.090 & -0.744 & $-2.884 * *$ & 0.890 & -0.373 & 0.403 & 0.172 \\
& $(8.550)$ & $(1.586)$ & $(1.097)$ & $(0.800)$ & $(0.815)$ & $(0.700)$ & $(1.181)$ \\
$\tau_{x}$ & -0.010 & -0.016 & -0.007 & -0.000 & 0.003 & 0.004 & 0.006 \\
& $(0.064)$ & $(0.015)$ & $(0.009)$ & $(0.010)$ & $(0.011)$ & $(0.011)$ & $(0.027)$ \\
Constant & 23.835 & 27.437 & 11.870 & 1.821 & -5.250 & -6.563 & -11.246 \\
& $(109.523)$ & $(27.143)$ & $(15.065)$ & $(17.637)$ & $(19.229)$ & $(19.539)$ & $(47.655)$ \\
Observations & 18 & 18 & 18 & 18 & 18 & 18 & 18 \\
$\mathrm{R}$-squared & 0.825 & 0.944 & 0.990 & 0.975 & 0.969 & 0.988 & 0.970 \\
\hline
\end{tabular}

Note: Standard errors in parentheses $* * * \mathrm{p}<0.01, * * \mathrm{p}<0.05, * \mathrm{p}<0.1$

the age differences in labor supply elasticity. Multi-generational models, such as the OLG, might need an array of age-specific parameters to reflect the behavioral differences across different stages of the life-cycle.

The estimates for the restricted labor supply model, equation (28), are reported in Table 5. As was discussed above, the parameter constraints allow us to examine the relative magnitude of intra- and inter-temporal elasticity by the ratio $\rho / \gamma$. This ratio also varies with age, as shown in the last row of Table 5. The aggregate time series estimate of this ratio is 1.7 (see $\rho / \gamma$ in Table 2). However, this estimate is confirmed only for the age groups 20-24, 25-34, 35-44, and 55-59, as their estimates are all greater than one. This suggests that the static elasticity of substitution between consumption and leisure outweighs the inter-temporal elasticity of substitution, in line with hypothesis 1 . However, consistent with hypothesis 5 , the equality test of $\rho$ and $\gamma$ (see F-test in Table 5) suggests that the intra- and the inter-temporal elasticity are statistically equal to each other, except among the oldest age group.

The $\rho / \gamma$ ratio for workers aged $60-64$ is -1.5 , which implies that the static elasticity outweighs the inter-temporal elasticity, and that it is further dominated by the income effects. This provides some supporting evidence for the backwardbending labor supply curve discussed previously; however, this estimate needs to be interpreted with caution because this age group is the most likely to be transitioning 
Table 4:

Estimation of age-specific time-series data, unrestricted Eq. (30)

\begin{tabular}{|c|c|c|c|c|c|c|c|}
\hline Variables & $16-19$ & $20-24$ & $25-34$ & $\begin{array}{c}35-44 \\
\left(e_{x, t} / M_{t}\right)\end{array}$ & $45-54$ & $55-59$ & $60-64$ \\
\hline $\ln \left(w_{x, t} / M_{t}\right)$ & $\begin{array}{c}1.169 * * \\
(0.529)\end{array}$ & $\begin{array}{c}1.539 * * * \\
(0.423)\end{array}$ & & & & $\begin{array}{c}0.978 \\
(0.670)\end{array}$ & \\
\hline $\ln \left(w_{x, t-1} / M_{t-1}\right)$ & $\begin{array}{l}-0.390 \\
(0.266)\end{array}$ & $\begin{array}{c}-1.047 * * \\
(0.475)\end{array}$ & & $\begin{array}{l}-0.583 \\
(0.611)\end{array}$ & & $\begin{array}{l}-0.475 \\
(0.621)\end{array}$ & $\begin{array}{l}-0.321 \\
(1.509)\end{array}$ \\
\hline $\ln \left(1+r_{t}\right)$ & $\begin{array}{l}-0.288 \\
(1.747)\end{array}$ & $\begin{array}{l}-0.486 \\
(0.619)\end{array}$ & $\begin{array}{l}-0.132 \\
(0.205)\end{array}$ & $\begin{array}{c}0.067 \\
(0.263)\end{array}$ & & $\begin{array}{c}0.092 \\
(0.288)\end{array}$ & $\begin{array}{l}-0.664 \\
(0.858)\end{array}$ \\
\hline $\ln \left(e_{x, t-1} / M_{t-1}\right)$ & $\begin{array}{c}0.109 \\
(0.448)\end{array}$ & $\begin{array}{r}0.731 \\
(0.1\end{array}$ & $\begin{array}{r}0.63 \\
(0 .\end{array}$ & $\begin{array}{r}1.20 \\
(0.3\end{array}$ & $\begin{array}{r}0.81 \\
(0 .\end{array}$ & $\begin{array}{c}1.209 * * * \\
(0.329)\end{array}$ & \\
\hline$\tau_{x}$ & $\begin{array}{c}-0.037 * \\
(0.019)\end{array}$ & $\begin{array}{c}-0.015^{* *} \\
(0.008)\end{array}$ & $\begin{array}{c}-0.013 * * * \\
(0.004)\end{array}$ & $\begin{array}{l}-0.004 \\
(0.004)\end{array}$ & $\begin{array}{c}-0.007 * * \\
(0.004)\end{array}$ & $\begin{array}{c}-0.011^{* *} \\
(0.005)\end{array}$ & $\begin{array}{l}-0.008 \\
(0.005)\end{array}$ \\
\hline Constant & $\begin{array}{l}68.748 * \\
(35.782)\end{array}$ & $\begin{array}{c}26.993 * * \\
(13.580)\end{array}$ & $\begin{array}{c}22.536 * * * \\
(7.016)\end{array}$ & $\begin{array}{c}6.240 \\
(8.527)\end{array}$ & $\begin{array}{l}11.587 * \\
(5.942)\end{array}$ & $\begin{array}{c}19.242 * * \\
(9.507)\end{array}$ & $\begin{array}{l}12.878 \\
(9.591)\end{array}$ \\
\hline & & & & & & & \\
\hline & 0.821 & & 0.50 & 0.025 & 0.027 & & 0.814 \\
\hline Overid sargan & 4.560 & 0.677 & 8.369 & 0.862 & & 0.919 & 1.237 \\
\hline Overid sargan p-value & 0.102 & 0.713 & 0.0152 & 0.650 & 0.189 & 0.632 & 0.539 \\
\hline
\end{tabular}

Note: Standard errors in parentheses

$* * * \mathrm{p}<0.01, * * \mathrm{p}<0.05, * \mathrm{p}<0.1$

Overid: Sargan over-identification test.

to retirement. Unfortunately, the data do not allow us to incorporate the economic incentives for retirement in the estimation; thus, it is very likely that the wage effect on the labor supply is overestimated, and that the income effects would diminish if pensions and/or other non-labor-related social benefits for the elderly were controlled for.

\section{Conclusion}

To assess the economic consequences of population aging and to evaluate the possible solutions to the problems which are expected to arise in conjunction with this trend, a thorough consideration of labor supply behavior is necessary. Hence, this paper examines the macro behavior of real wages and the labor supply in the Swedish labor market over the period 1985-2003. The descriptive analysis shows that the labor supply, as measured by the employment rate, is not strongly correlated with wages over the later working life, as the decline in the labor supply is too steep to be explained by wage change over old ages. Moreover, the age-wage profiles reveal a pronounced shift toward old age over time, whereas the age-employment profiles do not. These patterns cast doubt on the explanatory power of the ISH, at least for the later part of the life-cycle. 
Table 5:

Estimation of age-specific time series data, restricted Eq. (28)

\begin{tabular}{lccccccc}
\hline Variables & $\mathbf{1 6 - 1 9}$ & $\mathbf{2 0 - 2 4}$ & $\mathbf{2 5 - 3 4}$ & $\begin{array}{c}\mathbf{3 5}-\mathbf{4 4} \\
\ln \left(\boldsymbol{e}_{\boldsymbol{x}, t} / \boldsymbol{M}_{\boldsymbol{t}}\right)\end{array}$ & $\mathbf{4 5 - 5 4}$ & $\mathbf{5 5 - 5 9}$ & $\mathbf{6 0 - 6 4}$ \\
\hline $\ln \left(w_{x, t} / M_{t}\right)$ & 0.381 & $1.470^{* * *}$ & $0.593^{* *}$ & 0.331 & 0.099 & 0.236 & -0.230 \\
& $(0.253)$ & $(0.350)$ & $(0.231)$ & $(0.192)$ & $(0.088)$ & $(0.236)$ & $(0.332)$ \\
$\ln \left(w_{x, t-1} / M_{t-1}\right)$ & -0.381 & $-1.470^{* * *}$ & $-0.593^{* *}$ & -0.331 & -0.099 & -0.236 & 0.230 \\
& $(0.253)$ & $(0.350)$ & $(0.231)$ & $(0.192)$ & $(0.088)$ & $(0.236)$ & $(0.332)$ \\
$\ln \left(1+r_{t}\right)$ & -0.782 & $-0.870^{* * *}$ & $-0.479 * * *$ & $-0.272^{* *}$ & $-0.150^{*}$ & $-0.227 * *$ & $-0.929 * * *$ \\
& $(1.263)$ & $(0.239)$ & $(0.091)$ & $(0.100)$ & $(0.072)$ & $(0.088)$ & $(0.128)$ \\
$\ln \left(e_{x, t-1} / M_{t-1}\right)$ & 1.000 & 1.000 & 1.000 & 1.000 & 1.000 & 1.000 & 1.000 \\
& $(0.000)$ & $(0.000)$ & $(0.000)$ & $(0.000)$ & $(0.000)$ & $(0.000)$ & $(0.000)$ \\
$\tau_{x}$ & -0.001 & $-0.003^{*}$ & -0.001 & -0.000 & 0.000 & 0.000 & 0.001 \\
& $(0.004)$ & $(0.002)$ & $(0.001)$ & $(0.001)$ & $(0.000)$ & $(0.001)$ & $(0.002)$ \\
Constant & 1.103 & $6.496^{*}$ & 1.497 & 0.937 & -0.763 & -0.639 & -2.169 \\
& $(8.498)$ & $(3.082)$ & $(1.411)$ & $(1.294)$ & $(0.805)$ & $(1.532)$ & $(2.997)$ \\
Observations & 18 & 18 & 18 & 18 & 18 & 18 & 18 \\
F-test (p-value) & 0.777 & 0.247 & 0.677 & 0.792 & 0.693 & 0.973 & 0.00457 \\
$\rho / \gamma$ & -0.0253 & 2.377 & 1.474 & 1.438 & 0.318 & 1.083 & -1.496 \\
\hline
\end{tabular}

Note: Standard errors in parentheses

$* * * \mathrm{p}<0.01, * * \mathrm{p}<0.05, * \mathrm{p}<0.1$

F-test: equality test for hypothesis $5: H_{0}: \beta_{1}=\beta_{2}(\rho=\gamma)$

$\rho / \gamma$ : the relative magnitude of intra- to inter-temporal elasticity.

Combining the time-varying NTA age profiles with other macroeconomic variables allowed me to estimate the age-specific labor supply function, which is theoretically consistent with the overlapping generation framework. Unlike traditional macroeconomic analyses which rely on National Accounts to estimate a single elasticity for all demographic groups, the NTA data structure enabled me to estimate an array of quasi life-cycle parameters. This can serve as a new basis for calibrating the overlapping generation models with age-specific elasticities. Some key findings in my econometric analysis are summarized as follows.

(1) In the aggregate model, the estimated elasticity of the labor supply with respect to real wages is very close to that of Alogoskoufis (1987) and of Lucas and Rapping (1969). The economic magnitude of the inter-temporal elasticity of substitution is smaller than the economic magnitude of the intra-temporal elasticity of substitution, but there appears to be no statistical difference.

(2) The age-specific estimates show considerable variation in the short-run labor elasticity with respect to wages, as well as in the relative magnitude of interand intra-temporal elasticities across age groups. This implies that the elasticities estimated in traditional macroeconomic studies, e.g. Alogoskoufis (1987) and Lucas and Rapping (1969), can only reflect the labor supply behavior in a single representative household framework, but not in a multi-generation setting, such as the OLG. 
(3) The variation in age-specific estimates further suggests that an array of 'quasi' life-cycle parameters are needed in order to calibrate the OLG models for the multigenerational economy.

(4) The parameter equality test shows that the inter- and the intra-temporal elasticities are of about the same magnitude for most age groups. This suggests that the two elasticities are equally important in governing labor supply decisions over a large span of the working life, at least prior to age 60 .

I would like to conclude this paper by mentioning some limitations of this study and some potential extensions of the current analysis for future research. The patterns found for real wages and the labor supply, and for the relationship between the two, are in an age-specific period setting; therefore, they may be more literally interpreted as the working behavior in a quasi life-cycle framework. To better reflect the real life-cycle behavior, synthetic cohort studies are certainly preferable. This approach is, however, not readily implementable given the current state of the NTA time series for Sweden. Thus, an expansion of the data over a longer time horizon is desirable, and should be considered one of the core tasks in the future development of the NTA project.

This study stresses the wage impact on labor supply, but it ignores the value of outside options, such as schooling and retirement, which might be particularly important for younger and older workers. Therefore, one possible extension of the analysis in future research would be to investigate the rate of return to schooling and the economic incentives for retirement, and their potential impact on labor supply decisions.

The estimated elasticities in this study are very likely to be different from the findings of longitudinal studies using micro data. It is important to stress that the choice of the level of the analysis as well as of the type of data depend on the research question and the aim of the study. To examine detailed heterogeneity among individuals, micro-level analysis would certainly be preferred. Nonetheless, to apply the individual elasticities to macro models, such as the OLG-CGE, it is necessary to ensure the equivalence of the parameters in the two environments implied by the aggregation theory (Browning et al. 1999; Prescott and Wallenius 2011). For one of the purposes of this paper, providing some additional insights on the calibration of OLG models, my estimates are appropriate, as they correspond to the average of each representative generation.

\section{Acknowledgments}

Research funding was provided by the European Union's Seventh Framework Programme for research, technological development and demonstration under grant agreement NO. 613247, Centre for Economic Demography, and Knut Wicksell Centre for Financial Studies at Lund University, Sweden. I am grateful to Tommy Bengtsson for scientific guidance, and to Agneta Kruse, Åsa Hansson, Kirk Scott, Siddartha Aradhya, and the referees for their helpful comments. 


\section{References}

Alogoskoufis, G. S. 1987. On intertemporal substitution and aggregate labor supply. Journal of Political Economy 95(5), 938-960.

Auerbach, A. and L. Kotlikoff 1987. Dynamic fiscal policy. Cambridge University Press.

Barro, R. J. 1974. Are government bonds net wealth? Journal of Political Economy 82(6): 1095-1117.

Bengtsson, T. and K. Scott 2011. Population ageing and the future of the swedish welfare state. Population and Development Review 37, Supplement.

Börsch-Supan, A. 2003. Labor Market effects of population aging. Labour Special Issue, $5-44$.

Browning, M., L. P. Hansen, and J. J. Heckman 1999. Chapter 8, Micro data and general equilibrium models. Volume 1, Part A of Handbook of Macroeconomics, pp. 543-633. Elsevier.

Cain, G. 1966. Married women in the labor force: an economic analysis. Chicago: The University of Chicago Press.

Calvo, G. 1979. Quasi-Walrasian theories of unemployment. American Economic Review Proceedings 69: 102-07.

Coleman, T. 1984. Essays on aggregate labor market business cycle fluctuations. Ph.D. thesis, University of Chicago.

Diamond, P. 1965. National debt in a neoclassical growth model. The American Economic Review.

Fair, R. 1971. Labor force participation, wage rates, and money illusion. Review of Economics and Statistics 53: 164-68.

Harris, M. and H. Bengt 1982. A theory of wage dynamics. Review of Economic Studies 49: 316-33.

Heckman, J. J. 1993. What has been learned about labor supply in the past twenty years? The American Economic Review 83(2): 116-121.

Lazear, E. 1981. Agency, earnings profiles, productivity, and hours restrictions. American Economic Review 71: 606-20.

Lee, R. and L. Carter 1992. Modeling and forecasting U.S. mortality. Journal of the American Statistical Association 87(419): 659-671.

Lee, R. and R. D. Edwards 2001. The fiscal impact of population change. In Seismic shifts: the economic impact of demographic change, Number 46, Boston, pp. 190-219. Federal Reserve Bank of Boston conference Series.

Lee, R., D. Gretchen, and T. Miller 2011. The changing shape of the economic life-cycle in the United States, 1960 to 2003. In R. Lee and A. Mason (Eds.), Population aging and the generational economy, a global perspective, Chapter 15, pp. 313-326. Edward Elgar Publishing Limited.

Lee, S. and N. Ogawa 2011. Labor income over the lifecycle. In R. Lee and A. Mason (Eds.), Population aging and the generational economy, a global perspective, Chapter 5, pp. 109-135. Edward Elgar Publishing Limited.

Lucas, R. and L. Rapping 1969. Real wages, employment, and inflation. Journal of Political Economy 77(5): 721-754. 
Macurdy, T. E. 1981. An empirical model of labor supply in a life-cycle setting. Journal of Political Economy 89(6): 1059-85.

Mankiw, G. N., J. Rotemberg, and L. Summers 1985. Intertemporal substitution in macroeconomics. Quarterly Journal of Economics 100: 225-51.

Miles, D. 1999. Modelling the impact of demographic change upon the economy. The Economic Journal 109(452): 1-36.

Mincer, J. 1962. Labor force participation of married women. In U.-N. Bureau (Ed.), Aspects of labor economics, pp. 63-106. Princeton: Princeton University Press.

Modigliani, F. 1986. Life cycle, individual thrift, and the wealth of nations. The American Economic Review 76(3): pp. 297-313.

OECD 2011. OECD employment outlook 2011. Directorate for Employment, Labour and Social Affairs.

Oppen, J. and J. Vaupel 2002. Broken limits to life expectancy. Science, 1029-1031.

Pissarides, C. 1989. Unemployment consequences of an aging population: an application of insider-outsider theory. European Economic Review 33: 355-366.

Prescott, E. C. and J. Wallenius 2011. Aggregate labor supply. Federal Reserve Bank of Minneapolis.

Samuelson, P. 1958. An exact consumption loan model of interest with or without the social contrivance of money. Journal of Political Economy.

Skirbekk, V. 2003. Age and individual productivity: a literature survey. MPIDR.

Yellen, J. 1984. Efficiency wage models of unemployment. The American Economic Review 74(2): 200-205. 